\title{
Scaling up Action on Urban Sustainable Food Systems in the United Kingdom: Agenda Setting, Networking, and Influence
}

\author{
Mat Jones ${ }^{1, * \mathbb{D}}$ and Sarah Hills ${ }^{2}$ \\ 1 Department of Health and Applied Social Sciences, University of the West of England, Bristol BS16 1QY, UK \\ 2 Department of Geography and Environmental Management, University of the West of England, \\ Bristol BS16 1QY, UK; sarah.hills@uwe.ac.uk \\ * Correspondence: matthew.jones@uwe.ac.uk
}

Citation: Jones, M.; Hills, S. Scaling up Action on Urban Sustainable Food Systems in the United Kingdom: Agenda Setting, Networking, and Influence. Sustainability 2021, 13, 2156. https://doi.org/10.3390/ su13042156

Academic Editor: Christian Bugge Henriksen

Received: 3 December 2020 Accepted: 10 February 2021 Published: 17 February 2021

Publisher's Note: MDPI stays neutral with regard to jurisdictional claims in published maps and institutional affiliations.

Copyright: (c) 2021 by the authors. Licensee MDPI, Basel, Switzerland. This article is an open access article distributed under the terms and conditions of the Creative Commons Attribution (CC BY) license (https:/ / creativecommons.org/licenses/by/ $4.0 /)$.

\begin{abstract}
There has been an increasing focus on the potential of city-based initiatives to address the negative impacts of the global food system. Adopting a meso-level policy perspective, this study aimed to explore whether, how, and why the UK non-government organisation led Sustainable Food Cities (SFC) programme has influenced this food agenda at the level of city governance. The research fills a gap in our understanding of the detailed processes through which trans-local food networks influence the capacity of local food partnerships to effect change, sustain themselves, and through a collective effort, to shape the attention of national and international decision-makers. Based on documentary evidence from 29 of the most active member cities and interviews with a purposive selection of stakeholders, the analysis suggests that SFC provided a point of origin for solutions and inspiration on a major and complex issue. However, the absence of a national sustainable food policy framework and little formal national-government recognition of local food governance together with the paucity of funding opportunities threatens the long-term viability of local food partnerships and ultimately places significant constraints on the ability of the programme to effect long-lasting, systemic change.
\end{abstract}

Keywords: sustainable food systems; meso-level policy analysis; urban food governance; urban food partnerships; policy networks; advocacy coalitions

\section{Introduction}

Since the early 2000s, there has been increasing focus on the potential of city-based initiatives to contribute to the development of an alternative, socially just, healthy, and environmentally sustainable food system. The growth of place-based food activism has given rise to a growing body of research on placed-based initiatives such as food policy councils, food strategies, food networks, and food hubs [1]. Some of these studies have explored their origins and development over time and the lessons to arise from these experiences [2-5]. These municipal case studies show the importance of the personal characteristics of local leaders: their focus on convening cross-sectoral stakeholders, their skills in navigating through institutions, and their ability to build upon local issues. This research also points towards the fragility of leading networks of individuals and the challenges of maintaining momentum over time. Other recent work has compared different city-level initiatives. For example, Sonnino [6] analysed the documentation of 15 urban food strategies in the UK, the US, and Canada; Sussman and Bassarab [7] conducted a survey to help characterise 324 food policy councils in the USA and Canada; and Sibbing, Candel, and Termeer [8] analysed food policy integration in 31 Dutch municipalities. All studies reported increasing municipal interest in the development of food strategies. This emerging attention appears to reflect awareness of the distinctive role that cities can have in facilitating a systemic transformation of the food system. Sonnino [6] also identifies a common theme concerned with a holistic approach to sustainability that combines action on climate change, social justice, local and diverse economic development, and building 
community. This involves defining the food provisioning relationship between the city and its rural hinterland, as well as attention towards reconnecting different actors in the food system. Studies [6-8] in both North American and European contexts have found that urban areas differ considerably in terms of the progress made on envisioning and integrating thinking on food system sustainability into policy and practice. As well as capturing evolution at city level, these studies start to cast a light on the growth and interactions taking place between cities. However, such inter-city exchanges have been at the margin rather than the centre of this research.

The maturation of place-based food activism is reflected in the development of initiatives to connect local food policy groups into national and international networks, such as the Food Policy Network Project in the United States and the international Milan Urban Food Policy Pact [9]. There is a great deal of variation in the evolution, management, and resourcing of these networks, but central themes concern encouraging the ambition of places, providing frameworks for action, sharing good practice, and providing a collective voice on sustainable food to influence local, national, and international decision makers. Blay-Palmer, Sonnino, and Custo [10] and Levkoe [11] consider the potential for the sharing of knowledge and solutions across sustainable food networks. More recently Coulson and Sonnino [12], Moragues-Faus and Sonnino [13], Santo and Moragues-Faus [9], and Sonnino [14] have used a critical geography perspective to begin to explore the emergence, impact, and limitations of trans-local food networks. These studies draw on a range of theoretical perspectives-including urban ecology, governance theory, social movements, network analysis, and assemblage thinking - in order to facilitate a critical exploration of the nature and significance of food policy networks and their potential to address the unsustainability and inequalities of the current food system. The critical geography perspective that these authors adopt draws attention to the "dynamic and place-contingent" nature of food policy networks (assemblages) and the (uneven) geography of urban food governance in the UK [9]. This research attends to the role of micro- and macro-politics in constraining the transformative and emancipatory potential of food partnerships. This work also draws attention to the dynamic and place-contingent nature of food policy networks and the uneven geography of urban food governance in the UK and US. This literature points to the role of micro- and macro-politics in constraining the transformative and emancipatory potential of food partnerships [12,15].

Nevertheless, these exploratory studies leave gaps in our understanding of the detailed processes through which trans-local food networks influence the capacity of local food partnerships to effect change, sustain themselves, and through collective effort to shape the attention of national and international decision-makers. There has also been little consideration to date of the temporal dynamics of such networks-how their aims, management approaches, and impact evolve over time. With reference to the UK context, the starting point for our present study was to adopt a meso-level analysis, which Hudson and Lowe define as dealing "with how policies come to be made, who puts them on the policy agenda and the structure of the institutional arrangements in which policy is defined and eventually implemented" (p. 11) [16]. The subject of the study was the UK-based Sustainable Food Cities programme, as an example of a national trans-local initiative that seeks to support sustainable food system change in a range of urban contexts. The aim of the study was, therefore, to explore whether, how, and why the Sustainable Food Cities programme influenced food agendas and activism in UK urban areas.

\section{Materials and Methods}

\subsection{The Sustainable Food Cities Programme}

Sustainable Food Cities (SFC) is a UK programme funded by the Esmée Fairbairn Foundation (EFF). The first two phases were funded between 2012 and 2016 and 2016-2019. In late 2019, EFF and the National Lottery Community Fund provided funding for a fiveyear Phase 3 of the programme-rebranded as Sustainable Food Places-to work with both cities and a broader range of localities (see https: / / www.sustainablefoodplaces.org- 
accessed on 12 January 2021). Our present study focuses on the 2016-2019 period, with reference to 2012-2016 where appropriate.

Led by three national sustainable food organisations-the Soil Association, Sustain, and Food Matters-the aim of SFC has been to bring about a fundamental change in the food system. SFC has sought to catalyse, inspire, and support multi-sector, city partnerships to take a strategic and holistic approach to the sustainable food agenda. The scheme was inspired by UK city-level initiatives such as those taken in Bristol and Brighton, as well as overseas exemplars, such as the Toronto Food Policy Council in Canada [3].

The programme employed a range of activities including guidance, tools, and support based on an SFC strategic change model, an awards system, management and support around national campaigns, the provision of practical resources and grants, and the facilitation of a knowledge-sharing network. To become a member of the Sustainable Food Cities programme, cities had to demonstrate that they have a Local Food Partnership (LFP)_-“a cross-sector body that owns and drives forward the agenda" (p. 3) [17]. SFC made grants available to Local Food Partnerships to fund a local coordinator (usually part-time) and time-limited activities such as local food campaigns. The SFC Awards system provided a framework for development, and city members were encouraged to apply to the national body for the awards of Bronze, Silver, and Gold, with a standard set of criteria to demarcate each award level. The awards framework was organised with regard to six key issues:

- $\quad$ Promoting healthy and sustainable food to the public.

- Tackling food poverty (food insecurity), diet-related ill health, and access to affordable healthy food.

- $\quad$ Building community food knowledge, skills, resources, and projects.

- Promoting a vibrant and diverse sustainable food economy.

- Transforming catering and food procurement.

Reducing food waste and the ecological footprint of the food system. For each of the six issues, SFC specified criteria for nine action areas. To obtain an award, a multi-sector city partnership needed to provide documentary evidence against the criteria. Applications were assessed by a national SFC panel and awards needed to be renewed every two years.

\subsection{Methods}

This was a mixed methods study design. The data collection process is summarised in Figure 1. The initial stage of the research was informed by a realist approach [18] in which we sought to identify the main programme mechanisms and contextual influences that appeared to be linked to outcomes. Initially, in 2017, we collected the programme records from both the national SFC programme and local SFC city members. We examined these records to understand the connections between the design and delivery of activities at national and local levels. We also conducted semi-structured interviews with ten lead actors (eight SFC city coordinators and two national SFC leads), to understand their perspective on the programme's internal logic and theory of change. This learning shaped our subsequent data collection procedures and lines of enquiry; for example, in terms of evidence on local policy goals.

The next stages of the research between early 2018 and mid-2019 involved a documentary analysis of the programme records at a national and member city level. Member city programme records consisted of quarterly reports to the SFC national office, ad hoc reports on specific areas (such as campaigns), and applications for an award. These records provided detailed accounts of food-related governance, strategy, finance, and activity. This documentary evidence gave insight into the timeline and networking processes linked to sustainable food work within each SFC member city. Out of a total of 50 active SFC member cities, 29 provided a complete record of quarterly and ad hoc reports over the course of their participation in the programme. Drawing upon these 29, we gave specific attention to categorising the content of "policy goals"- the desired outcomes that a government or public body aims to achieve [19] (and see Sibbing, Candel, and Termeer [8] for a similar approach). 
In addition to documentary analysis, we undertook semi-structured in-depth interviews with a range of 25 local stakeholders from a purposive sample [20] of eight member cities. The interviews were conducted by telephone and took between 25 to $110 \mathrm{~min}$ (a mean of $45 \mathrm{~min}$ ). These cities were selected to provide diversity in terms of award status, duration of engagement, the maturity of local food partnership, city scale, and UK location. The interviewees included food partnership leads/coordinators and local authority, public health, civil society, and social enterprise representatives, as well as members of the national programme team. We selectively transcribed and thematically analysed [21] interview recordings with the assistance of NVivo, QSR International Pty Ltd. (Doncaster, Australia), Version 12, 2018, a qualitative analysis software tool. Programme records were content and thematically analysed [22] with the use of Excel worksheets and SPSS, IBM Corp. (Armonk, NY, USA), Version 26, a statistical software package. Our University Research Ethics Committee gave ethical permission to conduct the study.

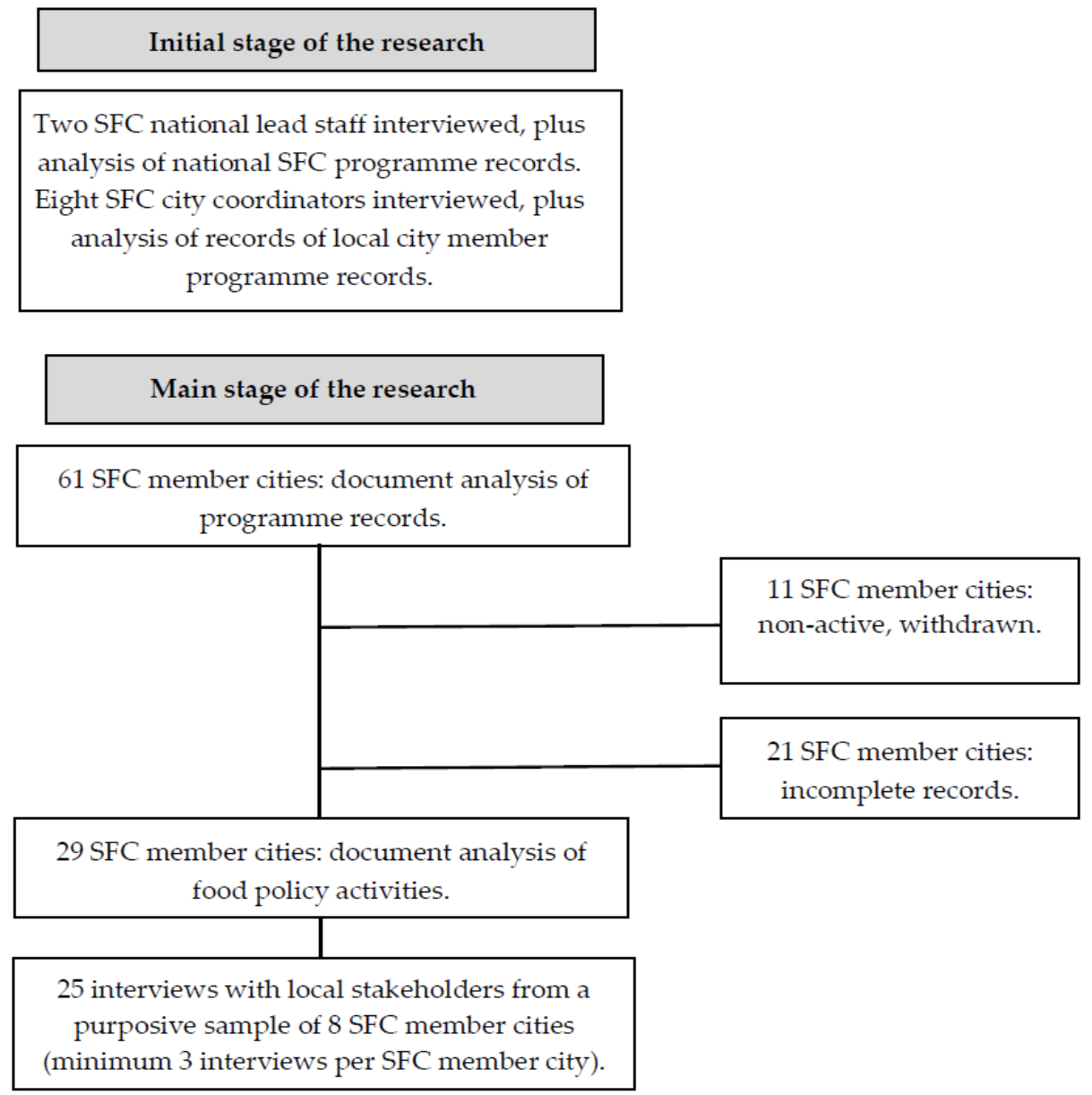

Figure 1. Summary of the process of data collection. SFC: Sustainable Food Cities.

\section{Results}

\subsection{Overview: Development of the National SFC Network}

Between 2012 and 2019, SFC evolved into a network comprising 50 active cities and other geographic areas. Just over half (54\%) of the active SFC partnerships $(27 / 50)$ had been members for five or more years, with more than two thirds (72\%) being active for three or more years. Member areas were widely distributed across the UK, with SFC members in all four UK nations with a wide geographical spread. In addition to some affluent areas, SFC established memberships in some of the UK's most economically deprived urban areas. The LFPs had varied organisational histories. Some were directly managed through local government departments, while others had more autonomous 
and self-organised origins in the work of individual activists and local non-governmental organisations (NGOs). LFPs, as networks of individuals, also varied substantially in scale, from six to over 100 members. The number of SFC award holders increased over the course of the programme, with over 33 members holding a Bronze, Silver, or Gold award in 2019. Given the level of documentary evidence and stakeholder authorisations required for award applications, SFC awards were a useful proxy indicator for the robustness and sustainability of local partnerships.

\subsection{Vision, Methodology, and Political Traction}

Many of the interviewees in LFPs and wider stakeholder groups reported that SFC helped to address the complexity, significance, and enormity of the challenge of changing the food environment. This was in a context where a meaningful public policy on sustainable food was felt by interviewees to be fragmented and weak. There was little evidence to suggest that the type of SFC integrated and whole systems approach would have happened organically and in such a sustained way in any of the case study cities. In many cases, SFC catalysed a partnership and strategic approach. The SFC approach resonated with, and provided a clear framework for, an approach that leading city stakeholders had already started to think about. In other cities, there was evidence that partnership groups had developed some elements of a strategic approach prior to contact with the SFC programme. Nevertheless, SFC was influential in these cities also because it helped to motivate, re-energise, develop, and reframe work that was already underway:

The big difference that being involved in the SFC has made is that it's moved us from just being concerned with the practical delivery of 'stuff' and into a more strategic arena. (X4)

The whole food systems approach of SFC enabled partnerships to reframe the narratives they used about sustainable food. For example, partnerships used the SFC award framework to advocate for local authority food procurement policies to include assessments of the value to the local economy, the environment, and public health. In turn, this whole systems approach helped to engage politicians and staff in local government departments who might have little interest in the sustainable food agenda had it been framed narrowly as either an environmental, social, or economic issue.

The SFC award framework has been tremendously influential in getting the attention of the city council. It helped us work more with the city council with different departments, like environmental health, food waste, and community development departments. (T2)

Interviewees felt that the SFC award scheme had been a tool for gaining buy-in, demonstrating success, and encouraging individual actors to be more ambitious. Part of the value has been in bringing together different areas of food-related activity across public, private, and voluntary sectors. This was a process that involved local SFC coordinators convening groups of actors that were not routinely in direct contract with one another. The view of many interviewees was that these groups were unlikely to have met and arrived at shared decisions without the incentive of the award and the work of local SFC coordinators. Outside these groups, the award also created a means to communicate the significance and value of this work to other key local stakeholders who were not directly involved.

\subsection{A Framework for Revising Local Policy Goals}

SFC membership starts with local food partnerships examining the connections and gaps on local strategic policy and service implementation plans to promote a more integrated perspective on food issues. As the programme developed, SFC has enhanced its advice and support to coordinators on engaging with local authorities on policy. Documentary analysis evidenced key actor successes in incorporating goals on food into multiple local policy domains. Between 2011 and 2019, 307 local policy goals on food were recorded in 29 SFC member cities, as shown in Table 1 . There were actions across a range of domains including the integrated and long-term strategic visions of local authorities in the form of the high-level Health and Wellbeing Strategy (e.g., Greenwich, London, UK, 2015) and the 
Local Plan (e.g., Carlisle, UK, 2015). Other policy actions took place in the context of local authority departments or public sector institutions, for example, with respect to food waste management or procurement. In Table 1, the Areas 1 to 6 tended to include specific policy targets, whereas Areas 7 to 10 tended to be more general policy aims.

Table 1. Local policy goals linked to food issues. Identified from an analysis of SFC award applications and coordinator reports between 2011 and 2019 for 29 SFC member areas.

\begin{tabular}{|c|c|c|c|c|c|c|c|c|c|c|}
\hline Policy Area & 2011 & 2012 & 2013 & 2014 & 2015 & 2016 & 2017 & 2018 & 2019 * & Total \\
\hline $\begin{array}{l}\text { 1. Reducing waste and carbon emissions } \\
\text { directly linked to food }\end{array}$ & 1 & 1 & - & 4 & 5 & 9 & 1 & 3 & 1 & 25 \\
\hline 2. Addressing food poverty and insecurity & - & 1 & 3 & 4 & 4 & 5 & 4 & 13 & 3 & 37 \\
\hline 3. Local food business development & - & - & 1 & 2 & 3 & 6 & 2 & 3 & 1 & 18 \\
\hline 4. Public sector food procurement & - & 2 & 2 & 3 & 2 & 6 & 13 & 18 & 2 & 48 \\
\hline 5. Promoting food-related public health & - & 2 & 3 & 5 & 1 & 5 & 6 & 9 & 4 & 35 \\
\hline $\begin{array}{l}\text { 6. Spatial planning and environmental goals } \\
\text { relating to food }\end{array}$ & - & 2 & - & 3 & 4 & 1 & 3 & 5 & 2 & 19 \\
\hline $\begin{array}{l}\text { 7. Establishing a multi-sector } \\
\text { food partnership }\end{array}$ & 1 & 1 & 4 & 5 & 6 & 4 & 8 & 1 & - & 31 \\
\hline $\begin{array}{l}\text { 8. Local authority food charter and food } \\
\text { action planning }\end{array}$ & - & 1 & 2 & 6 & 11 & 6 & 11 & 10 & 6 & 53 \\
\hline $\begin{array}{l}\text { 9. City-wide and corporate commitment to an } \\
\text { integrated food policy }\end{array}$ & - & - & 1 & - & 5 & 3 & 4 & 7 & 2 & 22 \\
\hline $\begin{array}{l}\text { 10. Climate emergency declaration, including } \\
\text { reference to the food system }\end{array}$ & - & - & - & - & - & - & - & 3 & 16 & 19 \\
\hline Annual count & 2 & 10 & 16 & 32 & 41 & 45 & 52 & 72 & 37 & 307 \\
\hline
\end{tabular}

${ }^{*}$ Note: 2019 is for 5 months of records only.

Under SFC's recording systems, the specific influence of SFC and local food partnership actors was not necessarily straightforward to trace. Under-recording of how local policy goals were developed may mean that our analysis under-reports the influence of SFC and local food partnerships. However, with improved recording systems over the course of the programme, an increasing number of goals were becoming linked to the influence of SFC at the local level. Further evidence from interviews in eight SFC member cities showed that lead actors had been actively drawing upon SFC guidance on local policy agenda setting, formulation, and adoption. Consequently, interviewees felt that partnerships had been able to lobby with more confidence and skills to incorporate food issues into high-level strategic plans of local authorities.

\subsection{Building Local Organisational Capacity through Funding}

One of the key goals of the SFC programme has been to support partnerships to reach a position of financial independence and sustainability. The ultimate vision had been that SFC should move from a centrally funded programme to an autonomous, mature, and resilient movement with the capacity to generate its own funding into the long term. The financial analysis of 29 SFC city members showed that the programme has leveraged additional funding. From the initial grant allocation of GBP 1,698,186, the programme and local partnerships raised an additional GBP 3,540,939 in cash and in-kind contributions. This represented a return of over GBP 2 for every GBP 1 investment by the programme funder. Of the 25 partnerships that received SFC coordinator funding, the majority (72\%) had been successful in leveraging funding in addition to a compulsory grant match. These contributions were to support core partnership functions as well as specific projects in areas including food growing, food education, and food insecurity. There were cases of sizeable sums awarded to partnerships. Nevertheless, funding remained a significant concern for SFC partnerships and outside of the SFC grants, the majority of partnerships experienced ongoing challenges in identifying and pursuing potential sources of income to sustain core personnel and functions. 


\subsection{Direct Support for Local Food Projects}

Analysis of 29 SFC member cities revealed that SFC-funded coordinators and partnerships initiated and augmented a considerable volume and variety of food programmes, projects, and activities. At the level of individual city members, coordinators directly helped these initiatives through match-making; bid writing, project planning, and technical advice; advocacy and representation; direct delivery and management; support to obtain funding; and publicity and marketing. Some initiatives went beyond immediate effects on direct participants to have a wider strategic impact on multiple groups of stakeholders within the area of an SFC member city. For example, several partnerships are working to increase the consumption of locally produced food and help create better links between growers, producers, and potential markets. One partnership developed a food-processing, storage, and distribution hub to bring these groups together. Other examples included the scaling up of school food poverty projects or catering procurement systems within the city areas.

\subsection{Replication of Practice, Innovation Transfer, and Skills Development}

For city-level action on food issues, sharing ideas could be particularly important given the complexity of the field, a deficit of well-established precedents and models for practice, and the scale and diversity of innovative thinking. SFC offered several mechanisms for the exchange of learning, including open-access award application records, regular harvesting and dissemination of best practice examples, peer-to-peer communication platforms, inperson network events, and direct signposting work. Instances of transfer of practice included a business commitment badge scheme, the dissemination of effective clauses to protect local food production in local authority plans, and terms of reference and technical procedures for food procurement groups. SFC therefore offered a source of professional development in a field that, for some, was patchy in the provision of opportunities. This involved specialist and technical support, for example, on running campaigns, as well as more general training:

If there is a challenge or a difficulty we do a shout out to SFC. For example, our local authority always asks us whether things we want to do have been done somewhere else. (SFC) has helped us locate case studies of best practice. The central resources are really helpful. (V2)

Knowledge sharing through the SFC network of member cities consisted of, for example, sharing of existing policies and strategies for bringing food into procurement or spatial planning policy, which has been one of the particularly useful benefits of the network. This enabled coordinators to feel more confidence about initiating discussions with local government officers and to respond to formal consultation rounds. In some cases, policies and strategies from other places were being forwarded on to local government officers. This provided practical support in how to construct policy documents and alsobecause these policies existed elsewhere-added credibility to those who were lobbying for change.

\subsection{Scaling Public Engagement through Campaigns and Media Channels}

Throughout the programme, SFC sponsored a series of campaigns. With little action at national policy levels, SFC coordinated action across a wide network of local areas to bridge gaps between grassroots campaigns. "Sugar Smart", for example, aimed to build awareness of the links between sugar consumption and ill health and to reduce sugar overconsumption. SFC national partners have developed the infrastructure behind the campaign for local area leads, and SFC provided financial support for SFC members to deliver the initiative. By March 2019, over 1500 organisations had pledged action to reduce sugar over-consumption. The campaign has driven a number of actions, including a decision by Coca-Cola to scale back its Christmas truck tour. This followed coordinated Sugar Smart protests in 2018, a joint letter with Healthy Stadia and 60 signatories to phase out of unhealthy sponsorship in football in 2018, and a commitment by 40 member Local Authority Working Groups to restrict High Fat, Salt, and Sugar advertising and to promote 
healthier advertising in 2018. The latter helped drive the decision by Transport for London to ban junk food advertising in early 2019.

A strong theme from the interviewees concerned the value of campaigns in bringing public attention to key issues and, in so doing, to the partnership itself. These obtained much greater traction as part of wider national work:

Sustainable Food Cities was a big success, it was a sort of a bridgehead from the local authority out into the wider region and into the whole public procurement system. It was a big eye-opener how quite a small campaign could go so far. (Z9)

The protest against the Coca Cola Truck wasn't even on our radar. It was only because of being part of an email network forum that was set up by SFC that we discovered that resources were available (to lead local action). We got a fantastic amount of media attention. (Q7)

\subsection{Scaling Influence in National Arenas}

SFC member cities engaged in several policy processes in the UK and devolved national governments. At the UK level, there is some evidence of influence in the field of food insecurity. In 2016, the work of SFC was reported in a parliamentary consultation document on strategies to improve action on access to healthy food. Subsequently, the work of SFC has been incorporated into two government agency publications as an example of good practice and resources for local government work on a healthier food environment and a whole-systems approach to obesity. In late 2018, SFC city members worked with the national government to prepare for different Brexit scenarios. In the devolved national government contexts, SFC achieved some recognition as a new local model for cross-sector governance; for example, through motions in the Welsh Assembly and the Scottish Parliament.

\subsection{Barriers and Challenges}

There was a strong sense from interviewees that SFC had the potential to influence major change, but for this to happen significantly, more resources needed to be drawn into the network. This sentiment was felt most acutely in more established SFC member cities that have invested in governance and strategy, and have identified priority areas for action. As one interviewee argued, there were difficulties in making progress in the absence of a more supportive policy context:

When you are working as a frontline organisation as a partnership at the coal face, it is hard to see how much further forward we can get without firm policy backing. (X4)

Limited resource and authorisation were problems in their own right but were also issues that contributed towards staff burnout and turnover according to interviewees. This in turn slowed progress at the local level. Of the 61 places that have been members of the network since the beginning of the programme, 11 have become dormant and five of these have had their membership revoked. Evidence from the monitoring reports showed that these cities had difficulties sustaining strategic activity on food given limited funding and mainstream policy support. This was also discussed in relation to SFC being perceived as something that might not be as attractive to areas with high deprivation and smaller towns that might struggle to perceive the relevance of a programme. The implication was that the SFC was historically weighted towards southern areas of greater affluence, or cultural dynamism.

If you look at the current network members, a lot of them are very big places, your

'Bristols,' your 'Londons'. I think the biggest hole is post-industrial northern towns.

(They) are quite under-represented, which is a shame because there is an awful lot to get out of it. (Z4)

Some interviewees felt that the parameters and underlying assumptions of the SFC framework, award, and campaigns criteria did not reflect local circumstances. Interviewees suggested that the award system could discriminate against smaller and more deprived 
areas and in some cases made some culturally biased assumptions about what constitutes sustainable food. Lack of engagement and a disconnection with large food businesses was also raised. Interviewees from more established member cities felt that many innovations were the consequence of city-level work, as opposed to work led from the national level. Other areas traced their current work back to local network and partnership activities over a much longer period before the creation of SFC:

If I'm being brutally honest, we've been giving more than we get from the network. But I think that's reasonable: we've benefited from early-stage SFC funding and it's up to us to share what we've learned with other areas. (X1)

\section{Discussion}

This study sought to assess the role of a national sustainable food programme in influencing place-based food governance, policy, and practice and in shaping sustainable food debate and policy at a greater scale. The results suggest that the SFC programme offered an agenda setting role through a broad strategic vision and a set of methods to enable local political engagement. These were linked to wide-ranging local government policy goal-setting, with occasional high impacts. Through sponsoring local coordinators, SFC was able to support multiple food projects at the city level and leverage additional funding to promote initiatives. The national programme provided a basis for the dissemination and sharing of practices and mechanisms for scaling up engagement with the public. The programme was linked to some changes in national government policy, and had formed a focus for knowledge exchange in research arenas. Some of the main areas of difficulty concerned the application of the award scheme, the duration and resourcing of campaigns, and a wider sense of the gulf between aspiration and capacity at the local level.

While there are a number of national networks with interests that touch on food issues, SFC was distinguished by its infrastructure for sustainable food advocacy, policy, and action. The SFC network model was distinguished by the scale and extent of its role in coordination, outreach and development, and representation at the national level. While stakeholders and the documentary evidence showed a wide range of beneficial influences of SFC, a small number of crosscutting themes highlight how SFC appears to have had the determining role in shaping changes at the local level. These can be understood as critical pathways where-in the absence of SFC - it is unlikely that impactful action would have occurred. Local efforts to influence the food agenda often require sustained and low visibility action over a period of several years [11]. In many, but not all cases, the SFC programme played a determining role in giving continuity of support to cities, not least through small funding to assist with coordinated action. Nevertheless, it was clear that some LFPs originated as autonomous self-directed networks, or as networks primarily facilitated or directed through local government-a scenario that has similarities to the origins of local environmental policy making in the UK [23].

In the absence of the SFC, it appears that action in most SFC cities would have consisted of fragmented initiatives addressing a limited range of sustainable food issues with limited impact. This is a reflection of a common limitation for locally led food policy initiatives more generally $[5,15,24]$. It appears that the arrival and development of the programme came at an opportune historical moment to build on the motivations of local actors who were seeking a national voice on urban food issues. A strength of the national network was therefore both the vertical and horizontal connections to amplify specific goals on food issues that are often marginal or pillarised at the local level [8]. At the city level, actors drew upon the SFC national agenda, gaining political access and traction in decision-making arenas. This appeared to reflect the maturation of the programme as it succeeded to navigate party-political alignment and sectoral interests.

Several campaigns and interventions are unlikely to have obtained coherence, successfully mobilised, and delivered at scale without the backing of SFC national actors. This is clearly in part due to the funding and specialist services on offer through SFC. However, it is dynamic of the relationship that appeared particularly important-which is one in which 
national and local actors exchange, innovate, and magnified their respective activities [25]. As Connelly and Beckie argue for local food initiatives, this draws attention to the importance of the "social infrastructure" that generates "a collective learning process leading to the rapid diffusion of knowledge and best practice" (p. 53) [26]. Our meso-level analysis also draws attention to the specific role of city-level coordinators with their pivotal role in terms of area-based knowledge, skills, and experience of local political processes. This does not get much attention in the more recent articles that refer to SFC, although these issues are highlighted more in some of the earlier work about individual food policy councils [2-4].

SFC has operated in an unfavourable economic and policy climate. The programme was delivered in the context of almost 10 years of government public spending austerity. Key potential funders of sustainable food work, such as local government and the Department for Environment, Food and Rural Affairs, have had their funding cut by approximately $50 \%$ and $40 \%$, respectively, in the period 2010/11-2019/20 [27]. Paradoxically, the growth of the national SFC programme has been accompanied by a substantial period of food policy activity in local government [28]. Despite the difficult context, SFC convened and promoted a detailed picture of action on food issues in UK cities and other local authority areas.

Addressing the food policy systemically and seeking to integrate economic, environmental, and social objectives is a pre-requisite for bringing about a sustainable food system [25]. In the UK as in many countries, national governments have tended towards a dis-integrated food policy development [29]. In so doing, they have failed to produce policy that seeks to create a food economy that fully addresses the multiple social and environmental challenges of the current food system. The weaknesses in national food policy created both challenges and opportunities at the local level. On the one hand, the lack of policy framework created a space for innovation and responses tailored to local conditions and needs. On the other hand, the lack of not just guidance on food policy, but the lack of resources and absence of food in policies that impact on and relate to health (such as planning, health, community, and economic development) has made the development of strategic, integrated, and impactful approaches to sustainable food out of reach at the local level. A persistent issue raised by leading actors from all parts of the SFC was, therefore, to draw attention to the substantial gap between aspiration and scope for action.

There are a number of implications for practice and policy development arising from this study. Food policy networks benefit from operating at multiple levels from attracting the attention of international bodies to working with local activists. It follows that networks also benefit from specialists, who operate in a specific policy or governance sphere, in addition to boundary spanners, who are effective in making connections between different arenas. The evolution of the SFC network shows that it has drawn in wider circles of actors who can contribute fresh perspectives and broaden the reach of the agenda. The growth of this increasingly diverse network needs to be accompanied by organised efforts to hold together communities of shared practice and the translation of ideas. For SFC, the role of the city-level coordinator has become increasingly pivotal in maintaining momentum. However, as the programme evolved, it has become clear that further guidance and support is needed about the nature, scope, and priorities for the role. The field would benefit from specialised professional development that is mapped to other practitioner roles in order to build greater workforce capacity. LFPs, with national support, have started to demonstrate effective influence on local policy actions. In this context, LFPs increasingly need to navigate their relationship with democratically mandated political processes. SFC now works with partnerships operating at different scales of governance, from city regions to sub-local authority municipalities. Moving forward, SFC will need to further optimise the programme for a variety of members, and possibly, following the case of London, increasingly work with nested multi-level partnerships.

There are a number of limitations to this study. Due to withdrawal or temporary suspension, we did not have a full account of the activities in 32 of the 61 urban areas that participated in the SFC programme. While we were able to capture some of the reasons 
for limited engagement, the main focus of this study was not on this group. This means that the current study has a stronger emphasis on city members that have successfully maintained their engagement with the SFC programme. The comprehensiveness and detail of programme reports from SFC city members was variable. This means that the study is unlikely to have captured all policy connections and influences within and between SFC city members. Nevertheless, the study builds upon a large set of data over an eightand-a-half-year period. The retrospective focus of interviews may have been a source of bias, although we were able to corroborate many claims against the programme written records. Some leading implications for further research are the need to undertake further contemporaneous investigation into the early evolution of local food partnerships and their engagement with trans-local partnerships, and to explore the circumstances in which such partnerships disband or struggle to develop over time.

\section{Conclusions}

Since its inception, SFC evolved into an increasingly stable network of active member cities and other geographical areas in the UK. The study indicates that SFC shaped food policy actions at the local level. These can be understood in terms of critical pathways where, in the absence of SFC, it is likely that action in most SFC cities would consist of fragmented initiatives addressing a limited range of sustainable food issues with limited impact. A number of cross-cutting themes highlight how SFC has helped support change. These show that there have been particular benefits with respect to the continuity and evolution of support for network members, and the coherence of the framework in a field that tends towards fragmentation. SFC created a common language for change around a highly complex issue that is, itself, in a state of change. It is plausible that the sustainable food city agenda would have been subsumed by alternative policy framings in the absence of SFC. A notable feature of the last two decades has been an accelerated public discourse on food. This is one in which alternative, and often overlapping, ideas around the social, environmental, and economic credentials of food have shifted rapidly. SFC, especially with regard to urban geographies, has shaped how to think about a difficult subject. SFC developed and implemented a set of approaches for how change can take place in the food policy field. The broad SFC network showed how city-level action could bridge gaps between grassroots and higher-level action. This has been particularly challenging given the paucity of resources, the difficulty of knowing where to start, and a deficit of action at national policy levels.

Author Contributions: Conceptualisation, M.J. and S.H.; methodology, M.J. and S.H.; investigation, M.J. and S.H.; formal analysis, M.J. and S.H.; writing—original draft preparation, M.J. and S.H.; writing-review and editing, M.J. and S.H; funding acquisition, M.J. All authors have read and agreed to the published version of the manuscript.

Funding: This study was funded through the Esmée Fairbairn Foundation as part of a grant to evaluate Phase 2 of the Sustainable Food Cities programme.

Institutional Review Board Statement: The study was conducted according to the guidelines of the Declaration of Helsinki, and approved by the University of the West of England Research Ethics, Reference number: HAS.17.10.031.

Informed Consent Statement: All participants were asked to provide informed written consent.

Data Availability Statement: No supplementary data is available, although a project report is available from the authors by request.

Acknowledgments: We would like to thank the support of the Sustainable Food Cities national team and local coordinators for providing access to programme records and consenting to participate in the interviews for this study.

Conflicts of Interest: The authors declare no potential conflict of interest concerning the research, authorship, and publication of this article. 


\section{References}

1. Santo, R.; Bassarab, K.; Palmer, A. State of the Research: An Annotated Bibliography on Existing, Emerging, and Needed Research on Food Policy Groups; John Hopkins University: Baltimore, MD, USA, 2017.

2. Mendes, W. Implementing social and environmental policies in cities: The case of food policy in Vancouver, Canada. Int. J. Urban Reg. Res. 2008, 32, 942-967. [CrossRef]

3. Blay-Palmer, A. The Canadian Pioneer: The Genesis of Urban Food Policy in Toronto. Int. Plan. Stud. 2009, 14, 401-416. [CrossRef]

4. Carey, J. Urban and community food strategies. The case of Bristol. Int. Plan. Stud. 2013, 18, 111-128. [CrossRef]

5. Coplen, A.K.; Cuneo, M. Dissolved: Lessons learned from the Portland Multinomah Food Policy Council. J. Agric. Food Syst. Community Dev. 2015, 15, 91-107.

6. Sonnino, R. The new geography of food security: Exploring the potential of urban food strategies. Geogr. J. 2016, 182, 190-200. [CrossRef]

7. Sussman, L.; Bassarab, K. Food Policy Council Report 2016; Johns Hopkins University: Baltimore, MD, USA, 2016.

8. Sibbing, L.; Candel, J.; Termeer, K. A comparative assessment of local municipal food policy integration in the Netherlands. Int. Plan. Stud. 2019, 1-14. [CrossRef]

9. Santo, R.; Moragues-Faus, A. Towards a trans-local food governance: Exploring the transformative capacity of food policy assemblages in the US and UK. Geoforum 2019, 98, 75-87. [CrossRef]

10. Blay-Palmer, A.; Sonnino, R.; Custo, J. A food politics of the possible? Growing sustainable food systems through networks of knowledge. Agric. Hum. Values 2016, 33, 27-43. [CrossRef]

11. Levkoe, C.Z. The food movement in Canada: A social movement network perspective. J. Peasant Stud. 2014, 41, 385-403. [CrossRef]

12. Coulson, H.; Sonnino, R. Re-scaling the politics of food: Place-based Urban Food Governance in the UK. Geoforum 2019, 98, 170-179. [CrossRef]

13. Moragues-Faus, A.; Sonnino, R. Re-assembling sustainable food cities: An exploration of translocal governance and its multiple agencies. Urban Stud. 2019, 56, 778-794. [CrossRef]

14. Sonnino, R. The cultural dynamics of urban food governance. City Cult. Soc. 2019, 16, 12-17. [CrossRef]

15. Lever, J.; Sonnino, R.; Cheetham, F. Reconfiguring local food governance in an age of austerity: Towards a place-based approach? J. Rural Stud. 2019, 69, 97-105. [CrossRef]

16. Hudson, J.; Lowe, S. Understanding the Policy Process: Analysing Welfare Policy and Practice; Policy Press: London, UK, 2009.

17. Davies, S. Food Partnership Structures: Stories from Sustainable Food Cities. Governance Guidance. 2019. Available online: https: / /www.sustainablefoodplaces.org/Portals/4/Documents/Governance\%20and\%20Structures \%20Guide\%20FinalA M.pdf (accessed on 12 January 2021).

18. Pawson, R.; Tilley, N. Realistic Evaluation; Sage Publications: London, UK, 1997.

19. Henstra, D. The Tools of Climate Adaptation Policy: Analysing Instruments and Instrument Selection. Clim. Policy 2016, 16, 496-521. [CrossRef]

20. Robinson, O.C. Sampling in interview-based qualitative research: A theoretical and practical guide. Qual. Res. Psychol. 2014, 11, 25-41. [CrossRef]

21. Clarke, V.; Braun, V.; Hayfield, N. Thematic analysis. In Qualitative Psychology: A Practical Guide to Research Methods; Sage Publications: London, UK, 2015; pp. 222-248.

22. Bowen, G.A. Document analysis as a qualitative research method. Qual. Res. J. 2009, 9, 27. [CrossRef]

23. Hudson, J.; Lowe, S.; Oscroft, N.; Snell, C. Activating Policy Networks: A case study of local environmental policy-making in the United Kingdom. Policy Stud. 2007, 28, 55-70. [CrossRef]

24. Castellanos, C.D.; Jones, J.C.; Christaldi, J.; Liutkus, K.A. Perspectives on the development of a local food system: The case of Dayton, Ohio. Agroecol. Sustain. Food Syst. 2016, 41, 186-203. [CrossRef]

25. Pitt, H.; Jones, M. Scaling up and out as a pathway for food system transitions. Sustainability 2016, 8, 1025. [CrossRef]

26. Connelly, S.; Beckie, M. The dilemma of scaling up local food initiatives: Is social infrastructure the essential ingredient? Can. Food Stud. 2016, 3, 49-69. [CrossRef]

27. Institute for Fiscal Studies. English Local Government Funding: Trends and Challenges in 2019 and Beyond; IFS: London, UK, 2019. Available online: https:/ /www.ifs.org.uk/publications/14563 (accessed on 12 January 2021).

28. Morgan, K. Nourishing the city: The rise of the urban food question in the Global North. Urban Stud. 2015, 52, 1379-1394. [CrossRef]

29. Parsons, K.; Barling, D.; Lang, T. UK Policymaking Institutions and their Implications for Integrated Food Policy. Adv. Food Secur. Sustain. 2018, 3, 211-251. 